\title{
FAKTOR-FAKTOR YANG BERHUBUNGAN DENGAN TINGKAT DEPRESI PADA PASIEN KANKER YANG MENJALANI KEMOTERAPI DI RUMAHSAKT Dr. OEN SURAKARTA
}

\author{
Tunjung Sri Yulianti ${ }^{1}$, Listriana Intan Kurniawati ${ }^{2}$
}

\begin{abstract}
Background: Suffering from cancer is a prominent stimulus for patients, so it can clearly bring great mental stress and suffering to the patient. Cancer patients undergoing chemotherapy usually experience various symptoms as a result of the disease or from chemotherapy itself. These symptoms affect the patient both physically and emotionally and furthermore negatively affect the treatment. Depression is a common symptom in cancer patients that are difficult to detect. This condition can negatively affect the quality of life of patients. Patient response to cancer can be affected by past life experiences with the disease. Each client uses different coping strategies. Support provided, will provide great benefits for subsequent therapy, prognosis and improvement of patient's quality of life.

Objective: To know the factors related to depression level in cancer patients who underwent chemotherapy at Dr. OEN SURAKARTA Hospital.

Research subjects: Cancer patients undergoing chemotherapy.
\end{abstract}

Keywords: Frequency of chemotherapy, stage of cancer, coping mechanism, family support, depression level

\section{PENDAHULUAN}

Pasien kanker yang menjalani kemoterapi biasanya mengalami berbagai gejala sebagai akibat dari penyakit atau dari kemoterapi itu sendiri. Gejala ini mempengaruhi pasien baik secara fisik maupun emosional dan lebih jauh lagi memberikan pengaruh negatif terhadap pengobatan. Depresi merupakan gejala umum pada pasien kanker yang sulit dideteksi. Kondisi ini bisa memburuk dan berpengaruh negatif terhadap kualitas hidup pasien. Setiap klien menggunakan strategi koping yang berbeda-beda (Black dan Hawks, 2014). Jika pasien kanker tidak mendapat dukungan dari keluarga, maka diagnosis akan membuat pasien menderita ansietas, depresi dan emosi negatif lain, hingga masuk dalam krisis mental. Sedangkan jika dukungan diberikan, akan memberikan manfaat besar bagi terapi berikutnya, bagi prognosis serta peningkatan kualitas hidup pasien (Desen, 2011).

Berdasarkan hasil Riskesdas 2013 bahwa kasus penyakit Kanker di Indonesia tertinggi terdapat di Yogyakarta dengan prevalensi 4,1 perseribu penduduk, diikuti Jawa Tengah dengan prevalensi 2,1 per seribu penduduk, Bali dengan prevalensi 2 per seribu penduduk, Bengkulu dan Jakarta masingmasing 1,9 per mil. Dengan demikian jika penduduk Jawa Tengah tahun 2017 sejumlah 35 juta jiwa, berarti ada sekitar 70.000 penduduk yang menderita penyakit kanker.

Reaksi seseorang yang menderita kanker, salah satunya adalah depresi yang ditandai dengan murung, gundah atau sangat sedih, menderita, bahkan timbul ide atau perilaku pesimis (Desen, 2011). Depresi adalah salah satu bentuk gangguan kejiwaan pada alam perasaan (affective/mood disorder), yang ditandai dengan kemurungan, kelesuan, ketiadaan gairah hidup, 
perasaan tidak berguna, putus asa dan lain sebagainya (Hawari, 2011). Beberapa penelitian terkait yang telah dilakukan diantaranya adalah penelitian Triyoga (2011) pada pasien kanker serviks di RSUD Dr. Moewardi Surakarta yang memperoleh hasil bahwa ada hubungan lama menderita kanker dengan tingkat depresi pasien kanker serviks $(p=0.039)$, ada hubungan dukungan sosial dengan depresi pasien kanker serviks ( $p=$ $0,016)$, Sedangkan Fajriati, Chanif dan Rosidi (2013) pada pasien kanker yang menjalani kemoterapi di RS Roemani Semarang, memperoleh hasil bahwa terdapat korelasi antara dukungan sosial dengan tingkat kecemasan pasien yang akan menjalani kemoterapi dengan nilai $p=0.001$ dan nilai $r=$ 0.659 . Penelitian Wahyono, Rahayu dan Nurhidayati (2015) pada pasien kanker payudara yang menjalani kemoterapi di Rumah Sakit Islam Sultan Agung Semarang, diperoleh nilai $p=0.000$, sehingga ada hubungan yang bermakna antara dukungan keluarga dengan tingkat stres pasien kanker payudara yang menjalani kemoterapi. Begitu pula penelitian Suwistianisa, Huda dan Ernawaty (2015) pada pasien kanker yang dirawat di RSUD Arifin Achmad Riau juga menunjukkan hasil faktor dukungan keluarga mempunyai hubungan yang signifikan dengan tingkat depresi responden $(p=0.002)$.

Pasien kanker yang menjalani kemoterapi di RUMAH SAKIT Dr. OEN SURAKARTA, rata-rata 8-10 pasien per hari. Respon pasien saat kemoterapi berbeda-beda, beberapa pasien tampak cemas dan beberapa pasien yang lain terlihat tenang.

\section{TUJUAN PENELITIAN}

Untuk mengetahui faktor-faktor yang berhubungan dengan tingkat depresi pada pasien kanker yang menjalani kemoterapi di RUMAH SAKIT Dr. OEN SURAKARTA.

\section{METODE/DESAIN PENELITIAN}

Penelitian ini merupakan penelitian analitik dengan desain korelasi untuk mengetahui faktor-faktor yang berhubungan dengan tingkat depresi pada pasien kanker yang menjalani kemoterapi.

\section{POPULASI, SAMPEL DAN TEHNIK SAMPLING}

Populasi penelitian ini adalah seluruh pasien yang menjalani kemoterapi di ruang kemoterapi RUMAH SAKIT Dr. OEN SURAKARTA. Dengan accidental sampling diperoleh sampel 68 pasien yang menjalani kemoterapi pada saat penelitian dilaksanakan.

\section{HASIL PENELITIAN}

Hasil penelitian ini dapat dijabarkan sebagai berikut:

Tabel 1.

Karakteristik Responden

\begin{tabular}{lcc}
\hline Karakteristik & $\mathrm{f}$ & $\%$ \\
\hline Jenis kelamin & & \\
Laki-laki & 10 & 14.7 \\
Perempuan & 58 & 85.3 \\
Umur & & \\
< 40 tahun & 6 & 8.8 \\
य 40 tahun & 62 & 91.2 \\
Jenis Kanker & & \\
Ovarium & 21 & 30.9 \\
Cervic & 17 & 25 \\
Mamae & 13 & 19.1 \\
NHL & 4 & 5.8 \\
Recti & 3 & 4.4 \\
Colon & 3 & 4.4 \\
Endometrium & 2 & 2.9 \\
Lidah & 1 & 1.5 \\
Nasofaring & 1 & 1.5 \\
Parotis & 1 & 1.5 \\
Vulva & 1 & 1.5 \\
Ca Buli & 1 & 1.5 \\
\hline
\end{tabular}

Dari tabel di atas diperoleh informasi bahwa responden lebih banyak berjenis kelamin perempuan yaitu 58 orang (85.3\%). Sebagian besar responden berumur lebih dari 40 tahun (91.2\%). Sebagian besar 
responden mengalami Ca Ovarium yaitu 21 orang (30.9\%).

Tabel 2.

Distribusi Frekuensi Variabel

\begin{tabular}{lcc}
\hline \multicolumn{1}{c}{ Variabel } & $\mathrm{f}$ & $\%$ \\
\hline Stadium kanker & & \\
$\quad$ Awal (1-2) & 18 & 26.5 \\
$\quad$ Lanjut (3-4) & 50 & 73.5 \\
Frekuensi kemo & & \\
$\quad$ Awal (1-3x) & 40 & 58.8 \\
$\quad$ Lanjut ( $\geq$ 4x) & 28 & 41.2 \\
Mekanisme Koping & & \\
$\quad$ Adaptif & 57 & 83.8 \\
$\quad$ Maladaptif & 11 & 16.2 \\
$\quad$ Dukungan Keluarga & & \\
$\quad$ Baik & 52 & 76.5 \\
$\quad$ Kurang & 16 & 23.5 \\
$\quad$ Tingkat Depresi & & \\
$\quad$ Ringan (Minimal- & 53 & 77.9 \\
$\quad$ Ringan) & & \\
$\quad$ Berat (Sedang-Berat) & 15 & 22.1 \\
\hline
\end{tabular}

Sebagian besar responden yaitu 50 orang $(73.5 \%)$ mengalami kanker stadium lanjut, sebagian besar responden yaitu 40 orang (58.8\%) menjalani kemoterapi awal. Sebagian besar responden yaitu 57 orang $(83.8 \%)$ mempunyai mekanisme koping adaptif dan 52 orang $(76.5 \%)$ mempunyai dukungan keluarga yang baik. Sebagian besar responden mengalami tingkat depresi ringan (77.9\%).

Tabel 3.

Tabulasi Silang Variabel

\begin{tabular}{lcc}
\hline & \multicolumn{2}{c}{ Tingkat } \\
\cline { 2 - 3 } & Ringan & Berat \\
\hline \multirow{2}{*}{ Std. awal } & 15 & 3 \\
& $83.3 \%$ & $16.7 \%$ \\
Std. Lanjut & 38 & 12 \\
& $76.0 \%$ & $24.0 \%$ \\
\multirow{2}{*}{ Kemo Awal } & 30 & 10 \\
& $75.0 \%$ & $25.0 \%$ \\
Kemo Lanjut & 23 & 5 \\
& $82.1 \%$ & $17.9 \%$ \\
\hline
\end{tabular}

Dari tabel di atas dapat diketahui bahwa responden dengan kanker stadium awal maupun stadium lanjut lebih banyak yang mengalami tingkat depresi ringan. Responden yang menjalani kemoterapi awal maupun lanjut juga lebih banyak yang masuk kategori tingkat depresi ringan. Dari analisa statistik disimpulkan tidak terdapat hubungan antara stadium kanker dan tingkat depresi pada responden $(p=0.520)$ dan tidak terdapat hubungan antara frekuensi kemoterapi dengan tingkat depresi responden $(p=0.484)$.

Tabel 4

Tabulasi Silang

\begin{tabular}{lcc}
\hline \multirow{2}{*}{ Variabel } & \multicolumn{2}{c}{ Tingkat Depresi } \\
\cline { 2 - 3 } & Ringan & Berat \\
\hline Koping Adaptif & 50 & 7 \\
Koping & $87.7 \%$ & $12.3 \%$ \\
Maladaptif & 3 & 8 \\
Dukungan Klg & 27.3 & $72.7 \%$ \\
Baik & 51 & 1 \\
Dukungan Klg & $98.1 \%$ & $1.9 \%$ \\
kurang & 2 & 14 \\
\hline
\end{tabular}

Dari tabel di atas dapat diketahui bahwa responden dengan mekanisme koping adaptif lebih banyak yang mengalami tingkat depresi ringan yaitu 50 orang $(87.7 \%)$, responden dengan mekanisme koping maladaptif lebih banyak yang mengalami depresi berat yaitu 8 orang (72.7\%). Dukungan keluarga yang baik lebih banyak yang masuk kategori tingkat depresi ringan yaitu 51 orang (98.1\%) sedangkan responden dengan dukungan keluarga yang kurang lebih banyak yang masuk kategori depresi berat yaitu 14 orang $(87.5 \%)$. Terdapat hubungan antara mekanisme koping dan tingkat depresi pada responden $(p=0.000)$ dan terdapat hubungan antara dukungan keluarga dengan tingkat depresi responden $(p=0.000)$.

Dari analisa dengan regresi logistik ganda diperoleh hasil nilai Nagelkerke $R$ Square sebesar 0.878. Mekanisme koping dan dukungan keluarga secara bersama-sama memiliki pengaruh sebesar $87.8 \%$ dengan tingkat depresi responden. Sedangkan 
$12.2 \%$ dipengaruhi oleh faktor yang lain. Nilai OR (Odds Ratio) untuk mekanisme koping sebesar 5.285 dan dukungan keluarga sebesar 5.550. Dapat disimpulkan bahwa dukungan keluarga yang baik mempunyai pengaruh untuk menurunkan resiko depresi sebesar 5.5 kali. Sedangkan mekanisme koping yang baik mempunyai pengaruh menurun-kan depresi sebesar 5.2 kali.

\section{PEMBAHASAN}

Responden dengan kanker stadium awal maupun stadium lanjut lebih banyak yang mengalami tingkat depresi ringan. Sedangkan untuk frekuensi kemoterapi baik responden yang menjalani kemoterapi frekuensi awal maupun lanjut lebih banyak yang masuk kategori tingkat depresi ringan.

Kondisi yang terjadi pada responden ini dapat di pahami karena pasien yang mengalami kanker biasanya akan mengalami penolakan, perasaan sedih, terkejut dan cemas justru pada saat pertama kali diberitahu tentang penyakitnya. Setelah beberapa waktu biasanya pasien berusaha untuk menerima keadaannya dan mulai mencari alternatif pengobatan. Hal ini seperti yang dijelaskan oleh Desen (2011), pasien kanker saat didiagnosis menderita kanker dapat mengalami reaksi psikologis yang rumit dan kacau. Reaksi tersebut dapat berupa penolakan, ansietas, ketakutan, marah, depresi dan menyendiri. Sementara pasien yang mengalami kanker stadium lanjut dapat menunjukkan reaksi psikologis yang terbagi dalam tiga fase yaitu fase penolakan, fase ketakutan dan fase adaptasi dimana pada fase adaptasi ketakutan akan kematian secara bertahap lenyap, dan menjadi relatif stabil. Sebagian besar responden (73.5\%) mengalami kanker stadium lanjut, dan responden sebagian besar
(91.2\%) berumur 40 tahun ke atas (dewasa tengah dan dewasa lanjut). Pada umur yang demikian seseorang telah memiliki kematangan pribadi yang mempengaruhi respon terhadap keadaan dirinya. Menurut Erikson seseorang yang berada pada usia dewasa pertengahan dan lanjut telah mampu menerima makna kehidupan dan ketakterhindarkannya kematian. Sedangkan menurut Havigurst orang dewasa menerima dan menyesuaikan dengan perubahan fisiologis dalam tubuhnya, menyesuaikan dengan penurunan kekuatan fisik dan kesehatan (LeMone, Burke dan Bauldoff, 2016). Selain hal tersebut sebagian besar responden penelitian ini (76.5\%) juga mendapatkan dukungan keluarga yang baik sehingga mereka mampu melewati keadaan sakitnya dengan baik. Hal ini sesuai paparan dari Smeltzer dan Bare (2013) beberapa reaksi emosional akibat sakit dialami pasien dan keluarga misalnya depresi, kesepian, tidak berdaya, berduka, harapan, keberanian dan sebagainya. Bagaimana mereka mengalami dan mengekspresikannya tergantung pada kepribadian dasar pasien, persepsi terhadap situasi dan besarnya dukungan dari orang lain.

Sedangkan untuk frekuensi kemoterapi dalam penelitian ini tidak berhubungan dengan tingkat depresi. Responden yang menjalani kemoterapi frekuensi awal maupun lanjut lebih banyak yang masuk kategori tingkat depresi ringan. Menurut Rulianti, et al., (2013) pemberian kemoterapi dapat berpengaruh terhadap fisik maupun emosional pada pasien. Selain itu masalah yang sering muncul pada pasien kemoterapi adalah efek samping yang timbul akibat obatobatan kemoterapi.

Sebagian besar responden (58.8\%) menjalani kemoterapi awal yaitu 
kemoterapi yang pertama sampai ketiga. Pada saat ditanya efek samping yang dirasakan, sebagian besar responden merasa mual setelah kemoterapi akan tetapi hal ini tidak terlalu membebani psikologis responden. Hal tersebut bisa dipahami karena tingkat penerimaan responden terhadap penyakit dan pengobatan yang harus dilakukan cukup tinggi ditunjukkan dari koping mekanisme responden yang sebagian besar $(83.8 \%)$ memiliki koping yang adaptif. Hal ini sesuai dengan pernyataan dari Black dan Hawks (2014) bahwa klien-klien yang mahir memecahkan masalah atau memiliki koping efektif cenderung menghadapi realita, menghindari menyangkal berlebihan, tetap fleksibel, menerima dukungan, tetap berharap, dan optimis. Sedangkan menurut Desen (2011) derajat dan manifestasi reaksi psikologis terkait penyakit berkaitan langsung dengan jenis kelamin, usia, tingkat budaya, pangalaman hidup, pemahaman akan pengetahuan medis serta ciri pribadi.

Dari analisis regresi logistik ganda diperoleh nilai Nagelkerke $R$ Square sebesar 0.878. Mekanisme koping dan dukungan keluarga secara bersama-sama memiliki pengaruh sebesar $87.8 \%$ terhadap tingkat depresi responden. Nilai OR (Odds Ratio) untuk mekanisme koping sebesar 5.285 dan dukungan keluarga sebesar 5.550. Dukungan keluarga yang baik mempunyai pengaruh untuk menurunkan resiko depresi sebanyak 5.5 kali. Sedangkan mekanisme koping yang baik mempunyai pengaruh menurunkan depresi sebanyak 5.2 kali.

Hasil analisa statistik yang demikian dapat dipahami karena peran mekanisme koping dan dukungan keluarga terhadap pasien kanker cukup penting. Hal ini didukung pernyataan dari Black dan Hawks
(2014) bahwa klien-klien yang mahir memecahkan masalah atau memiliki koping efektif cenderung menghadapi realita, menghindari menyangkal berlebihan, tetap fleksibel, menerima dukungan, tetap berharap dan optimis. Klien yang bukan pemecah masalah yang baik akan menghindar dan menyangkal berlebih; mereka pesimis dan merasa tidak ada harapan.

Sedangkan menurut (Kozier, et al., 2011) setiap klien menggunakan strategi koping yang berbeda-beda. Koping dapat adaptif dan maladaptif. Koping yang berfokus pada masalah mengacu pada upaya memperbaiki situasi dengan membuat perubahan atau mengambil beberapa tindakan. Hal ini ditunjukkan pada semua responden yang segera mengambil tindakan yang tepat untuk berobat ke fasilitas pelayan kesehatan setelah didiagnosa kanker.

Koping yang berfokus pada emosi mencakup pada pikiran dan tindakan yang meredakan distres emosi. Koping yang berfokus pada emosi tidak memperbaiki situasi, tetapi setelah menggunakannya, individu sering kali merasa lebih baik. Pada penelitian ini sebagian besar responden (94\%) mengatakan setelah mengetahui penyakitnya mereka menangis meskipun setelah itu mereka mencoba untuk ikhlas dan menumbuhkan semangat untuk sembuh. Strategi koping juga dipandang sebagai strategi jangka panjang dan jangka pendek. Strategi koping jangka panjang dapat konstruktif dan realistis. Sebagai contoh, pada situasi tertentu, berbicara dengan orang lain mengenai masalah dan mencoba untuk mencari tahu lebih banyak mengenai situasi tersebut merupakan strategi jangka panjang. Semua responden penelitian ini menyampaikan atau membicarakan dengan orang lain terkait penyakit dan perawatannya. Sehingga 
mereka memperoleh masukan dan support yang baik.

Strategi jangka panjang yang lain termasuk strategi yang mencakup perubahan pola gaya hidup, seperti melakukan diet sehat, olahraga teratur, menyeimbang-kan antara waktu senggang dan waktu untuk bekerja atau menggunakan pemecahan masalah, bukan marah atau respons nonkonstruktif lain dalam pembuatan keputusan. Strategi tersebut bahkan dapat berpengaruh destruktif atau merusak pada individu. Contohnya adalah minum minuman beralkohol atau mengonsumsi obat-obatan, bermimpi dan mengkhayal. Sebagian besar responden penelitian ini (97\%) mengatakan mengubah pola hidupnya menjadi lebih sehat setelah didiagnosa kanker, tidak mengkonsumsi minumanan beralkohol dan berusaha menyelesaikan masalahnya dengan kepala dingin (tidak emosional dan marah-marah). Untuk variabel dukungan keluarga, $76.5 \%$ responden mempunyai dukungan keluarga yang baik, sedangkan nilai OR yang diperoleh sebesar 5.550. Hal ini menunjukkan bahwa dalam penelitian ini dukungan keluarga sangat besar pengaruhnya untuk menurunkan tingkat depresi responden. Hasil ini sesuai dengan paparan dari Black dan Hawks (2014) yang menyatakan bahwa dukungan keluarga sangat berpengaruh terhadap tingkat depresi penderita kanker. Keluarga yang banyak menyangkal, menunjukkan amarah kuat dan rasa bersalah, atau sangat menuntut berisiko untuk berdisfungsi. Jika pasien kanker tidak mendapat dukungan dari keluarga, maka diagnosis akan membuat pasien menderita ansietas, depresi dan emosi negatif lain, hingga masuk dalam krisis mental. Sedangkan jika dukungan diberikan, akan memberikan manfaat besar bagi terapi berikutnya, bagi prognosis serta peningkatan kualitas hidup pasien (Desen, 2011). Memberikan dukungan sosial dan memperbaiki daya kontrol diri klien membantu mengurangi kecemasan. Pengurangan stres dengan teknikteknik relaksasi dapat diajarkan. Berdiskusi dengan orang yang bertahan dari kanker mampu memberikan semangat ke banyak klien (Black dan Hawks, 2014).

Terkait dengan tugas keluarga dalam bidang kesehatan, hasil penelitian ini menunjukkan bahwa hampir semua keluarga responden melaksanakan tugas kesehatannya dengan baik. Keluarga dari semua responden mengenal dan mengetahui sejauhmana masalah kesehatan responden. Keluarga juga mengambil keputusan untuk segera mencari pengobatan untuk responden, melakukan perawatan yang dibutuhkan di rumah misalnya mengatur makan dan mengantar responden untuk kontrol atau kemoterapi. Keluarga responden juga menjalin komunikasi dan berkonsultasi dengan petugas kesehatan. Dari hal-hal tersebut maka dapat diketahui bahwa dukungan keluarga sangat baik terhadap responden, sehingga hal ini mampu memberikan dorongan dan menguatkan responden dalam menghadapi penyakitnya, mempunyai semangat untuk sembuh sehingga tidak sampai mengalami depresi yang berat. Hal ini sesuai dengan paparan dari Setiadi (2008) yaitu tugas keluarga dalam bidang kesehatan meliputi, pertama mengenal masalah kesehatan. Kedua, mengambil keputusan untuk melakukan tindakan yang tepat bagi keluarga. Ketiga, memberikan perawatan anggotanya yang sakit atau yang tidak dapat membantu dirinya sendiri karena cacat atau usianya yang terlalu muda. Keempat, 
mempertahankan suasana rumah yang menguntungkan kesehatan dan perkembangan kepribadian anggota keluarga. Dan yang terakhir, mempertahankan hubungan timbal balik antara keluarga dan lembaga kesehatan dengan memanfaatkan fasilitas kesehatan yang ada

Hasil penelitian ini senada dengan penelitian lain yaitu penelitian Triyoga (2011) pada pasien kanker serviks di RSUD Dr. Moewardi Surakarta yang memperoleh hasil bahwa ada hubungan dukungan sosial dengan depresi pasien kanker serviks ( $p$-value $=0.016)$, dukungan sosial lebih dominan berhubungan daripada lama menderita kanker terhadap tingkat depresi pasien kanker serviks $(p$-value $=0.007)$. Sedangkan penelitian Fajriati, Chanif dan Rosidi (2013) pada pasien kanker yang menjalani kemoterapi di RS Roemani Semarang memperoleh hasil bahwa terdapat korelasi antara dukungan sosial dengan tingkat kecemasan pasien yang akan menjalani kemoterapi dengan nilai signifikan sebesar 0.001 dan nilai $r=$ 0.659 . Penelitian Wahyono, Rahayu dan Nurhidayati (2015) pada pasien kanker payudara yang menjalani kemoterapi di Rumah Sakit Islam Sultan Agung Semarang, dengan hasil ada hubungan yang bermakna antara dukungan keluarga dengan tingkat stres pasien kanker payudara yang menjalani kemoterapi. Penelitian Suwistianisa, Huda dan Ernawaty (2015) pada pasien kanker yang dirawat di RSUD Arifin Achmad Riau juga menunjukkan hasil yang sama yaitu faktor dukungan keluarga mempunyai hubungan yang signifikan dengan tingkat depresi responden $(p=0.002)$.

\section{KESIMPULAN}

1. Tidak terdapat hubungan antara stadium kanker dengan tingkat depresi pada responden ( $p=$ 0.520).

2. Tidak terdapat hubungan antara frekuensi kemoterapi dengan tingkat depresi responden ( $p=$ 0.484).

3. Terdapat hubungan antara mekanisme koping dengan tingkat depresi pada responden $(p=0.000)$.

4. Terdapat hubungan antara dukungan keluarga dengan tingkat depresi responden $(p=$ 0.000)

5. Nilai Nagelkerke $R$ Square sebesar 0.878, sehingga mekanisme koping dan dukungan keluarga secara bersama-sama memiliki pengaruh sebesar $87.8 \%$ terhadap tingkat depresi responden.

6. Nilai Odd Ratio mekanisme koping adalah 5.285 dan dukungan keluarga adalah 5.550, dengan demikian mekanisme koping yang baik dapat menurunkan resiko depresi sebesar 5.2 kali dan dukungan keluarga yang baik dapat menurunkan resiko depresi sebesar 5.5 kali.

\section{SARAN}

1. Bagi pasien kanker yang menjalani kemoterapi disarankan untuk terus membangun koping yang adaptif agar mampu bertahan dalam kondisi sakitnya tanpa mengalami depresi.

2. Disarankan pada keluarga untuk terus memberikan dukungan baik fisik (material) maupun psikologis pada pasien agar terhindar dari resiko depresi yang dapat memperberat penyakit dan menghambat pengobatan yang dijalani.

3. Disarankan pada rumah sakit untuk membentuk Focus Group Discussion (FGD) bagi keluarga dan pasien kanker yang menjalani kemoterapi yang dibimbing oleh perawat atau 
psikolog klinis agar bisa menjadi sarana untuk berbagi, mendukung dan saling menguatkan serta memberikan penyuluhan yang diperlukan dengan harapan mampu meningkatkan kualitas hidup pasien kanker dan menambah jumlah survival kanker.

4. Disarankan untuk peneliti selanjutnya agar melakukan pembatasan karakteristik responden misalnya dari jenis, stadium, lama menderita kanker maupun karakteristik yang lain sehingga diperoleh responden yang homogen dan mendapatkan hasil penelitian yang lebih optimal.

\section{DAFTAR PUSTAKA}

Badan Penelitian dan Pengembangan Kesehatan. 2013. Hasil Riskesdas 2013. Kemenkes, Jakarta.

Black, J. M. dan J. H.Hawks. 2014. Keperawatan Medikal Bedah Manajemen Klinis untuk Hasil yang Diharapkan. Alih Bahasa Rizal Azhari Nampira dan Shanti Citra Eka. Salemba Medika, Jakarta.

Desen, W. 2011. Buku Ajar Onkologi Klinis Edisi II. Alih Bahasa Willie Japaries. Badan Penerbit FKUI, Jakarta.

Fajriati, A., Chanif dan A. Rosidi. 2013. "Hubungan Dukungan Sosial dengan Tingkat Kecemasan pada Pasien Kanker yang akan Menjalani Kemoterapi di RS Roemani Semarang". http://digilib.unimus.ac.id. Diakses pada tanggal 3 Oktober 2017.

Hawari, D. 2011. Manajemen Stres Cemas dan Depresi. Edisi II. Balai Penerbit FKUI, Jakarta.
Kozier, B., et al. 2011. Buku Ajar Fundamental Keperawatan Konsep, Proses, \& Praktik. Alih Bahasa Esty Wahyuningsih, et al. Buku Kedokteran EGC, Jakarta.

LeMone, P., K. M. Burke dan G. Bauldoff. 2016. Buku Ajar Keperawatan Medikal Bedah. Alih Bahasa. Barrarah Bariid dan Nike Budhi Subekti. EGC, Jakarta.

Rulianti, M. R., D. Almasdy dan A. W. Murni. 2013. "Hubungan Depresi dan Sindrom Dispepsia pada Pasien Penderita Keganasan yang Menjalani Kemoterapi di RSUP DR. M. Djamil Padang".

http://vufind.uniovi.es/

Record/oai:doaj.orgarticle:53 de610917354d719e30d80ba f8c81a0. Diakses pada tanggal 16 Oktober 2017.

Setiadi, 2008. Konsep dan Proses Keperawatan Keluarga. Graha IImu, Yogyakarta.

Smeltzer , S. C. dan B. G. Bare, 2013. Buku Ajar Keperawatan Medikal Bedah Brunner dan Suddart. Edisi VIII. Alih Bahasa : Agung Waluyo, et al. EGC, Jakarta.

Suwistianisa, R., N. Huda dan J. Ernawaty. 2015. "Faktorfaktor yang Mempengaruhi Tingkat Depresi pada Pasien Kanker yang Dirawat di RSUD Arifin Achmad Provinsi Riau". https://jom.unri.ac.id/index.ph p/JOMPSIK/article/view/8320 Diakses tanggal 1 Oktober 2017. 
••KOsคเค•• JIK. Vol. 6 No. 2 November 2018

Triyoga, H. 2011. "Faktor-Faktor yang Berhubungan dengan Tingkat Depresi pada Pasien Kanker Serviks di RSUD Dr. Moewardi Surakarta". https://scholar.google. co.id/scholar?start=10\&q=fak tor+yang+berhubungan+den gan+tingkat+depresi+pada+p asien+kanker+serviks+di+rsu $\underline{d}+\mathrm{dr}+$ moewardi\&hl=id\&as $\mathrm{s}$ $\mathrm{dt}=0,5 \& a s$ vis $=1$. Diakses 1 Oktober 2017.

Wahyono, D. Rahayu dan T. Nurhidayati. 2015. "Dukungan Keluarga terhadap Tingkat Stres Pasien Kanker Payudara yang Menjalani Kemoterapi di Rumah Sakit Islam Sultan Agung Semarang". https://digilib.unimus.ac.id/gdl .php?modbrowse\&

op=read\&id=jtptunimus-gdlwahyononim-8371. Diakses pada tanggal 1 Oktober 2017.

${ }^{1}$ Dosen Akper Panti Kosala

Surakarta

${ }^{2}$ Mahasiswa Akper Panti Kosala

Surakarta 